\title{
Frequency spectrum of surface plasmon-polariton waves: influence of Coulomb correlations
}

\author{
Kostrobij P. P., Markovych B. M., Polovyi V. Ye. \\ Lviv Polytechnic National University, \\ 12 S. Bandera Str., 79013, Lviv, Ukraine
}

(Received 15 February 2020; Revised 17 April 2020; Accepted 20 April 2020)

\begin{abstract}
The model that describes the influence of Coulomb interaction between electrons (Coulomb correlations) on a frequency spectrum of plasmon-polariton waves in electroneutral structures dielectric/metal/dielectric is investigated. It is shown that for atomically thin metal films (ATMF), such correlations affects both the quantum-dimensional behavior of the frequency spectrum as a function of the thickness of the metal film and significantly improves the correlation of theoretical calculations and experiment.
\end{abstract}

Keywords: surface plasmons, plasmon spectrum, metal layer thickness, dielectric permittivity, electroneutrality.

2010 MSC: 78A50, 78-05, 78A25

DOI: $10.23939 / \mathrm{mmc} 2020.01 .140$

\section{Introduction}

Investigation of plasmon-polariton waves (SPPs) that propagate along the dielectric/metal interface [1] is an important problem nowadays for both experimental studies [1-3] and studies of mathematical models of SPPs waves due to their widespread use in the subwavelength optics technologies.

Mathematical modeling of the propagation processes of SPPs waves, of their frequency spectrum, etc., is based on the methods of classical electrodynamics using the Drude model [1] for describing the time dispersion of the dielectric function $\varepsilon$ of a metal layer.

It is known $[1,4]$ that the Drude model (except significant drawback - neglect of spatial dispersion in $\varepsilon(\omega))$ describes well the behavior of $\varepsilon(\omega)$ for metal layers with the thickness that exceeds $1000 \mathrm{~nm}$ [1].

Current state-of-the-art for the design and use of metal/dielectric or dielectric/metal/dielectric structures $[2,3,5-7]$ makes it possible to obtain metal structures with the thickness $5<l<100 \mathrm{~nm}$. For such structures, one should take into account not only quantum-size effects [8] but also the presence of an exponential "tail" of electron density [5-7,9] (so-called quantum spill-out effect) in near-surface areas of the contact metal/dielectric. This inevitably leads to a description of the influence of spatial dispersion of the dielectric function $\varepsilon$ of the metal layer due to the taking into account of the conditions of electroneutrality and Coulomb correlation [10,11].

This paper proposes and investigates a mathematical model for considering the influence of Coulomb correlations in atomically thin metal films (ATMF) of the $10-100 \mathrm{~nm}$ thickness due to the influence of these correlations on the chemical potential $\mu$ for the jellium model of ATMF taking into account the conditions of electroneutrality $[8,10]$.

The obtained results for the frequency spectrum we have compared with experimental data and it is shown that taking into account Coulomb correlations leads to a significant improvement in the correspondence of theoretical and experimental results compared with the results that we obtained earlier in [12]. 


\section{Problem formulation}

A mathematical model for describing the propagation of SPPs waves in a dielectric/ATMF/dielectric structure based on the use of the Maxwell's equations system [1,13] with nonlocal relations between the electric field strength vector $\boldsymbol{E}$ and the induction vector $\boldsymbol{D}$ is given in [12]. In the proposed mathematical model, it is assumed that the dielectric function $\varepsilon_{2}$ of an ATMF, in contrast to the frequency-dependent dielectritic functions $\varepsilon_{1}$ and $\varepsilon_{3}$ of dielectrics, is characterized by time and spatial dispersion.

Applying to Maxwell's equations the Fourier transform with respect to the time $t-t^{\prime}$ and to spatial vector $\boldsymbol{r}_{\|}-\boldsymbol{r}_{\|}^{\prime}$ and considering the electromagnetic waves of TM polarization [1], viz. $\boldsymbol{E}=\left(E_{x}, 0, E_{y}\right)$, $\boldsymbol{H}=\left(0, H_{y}, 0\right), \boldsymbol{H}(\boldsymbol{r})=\boldsymbol{H}(z) e^{i k_{x} x}, k_{x}$ is a wave vector in the direction of propagation, we obtain the following system of wave equations $\boldsymbol{H}$ [1]:

$$
\begin{gathered}
\frac{\partial^{2} H_{y}(z)}{\partial z^{2}}+\left(k_{0}^{2} \varepsilon_{1}(\omega)-k_{x}^{2}\right) H_{y}(z)=0, \\
\frac{\partial^{2} H_{y}(z)}{\partial z^{2}}+\left(k_{0}^{2} \varepsilon_{2}(\boldsymbol{k}, z, \omega)-k_{x}^{2}\right) H_{y}(z)=0, \\
\frac{\partial^{2} H_{y}(z)}{\partial z^{2}}+\left(k_{0}^{2} \varepsilon_{3}(\omega)-k_{x}^{2}\right) H_{y}(z)=0,
\end{gathered}
$$

where

$$
\varepsilon_{i}\left(\boldsymbol{r}_{\|}-\boldsymbol{r}_{\|}^{\prime}, z, z^{\prime}, t-t^{\prime}\right)=\frac{\Omega}{(2 \pi)^{3}} \int_{-\infty}^{\infty} d \omega \int_{\Omega} d \boldsymbol{k} \varepsilon_{i}\left(\boldsymbol{k}, z, z^{\prime}, \omega\right) e^{-i\left(\boldsymbol{k}, \boldsymbol{r}_{\|}-\boldsymbol{r}_{\|}^{\prime}\right)-i \omega\left(t-t^{\prime}\right)},
$$

here $k_{0}=\omega / c, c$ is the speed of light in vacuum, $\Omega=\mathbb{R}^{2}$ is a domain of vector $\boldsymbol{k}=\left(k_{x}, k_{y}\right)$.

Hereafter, while considering $\varepsilon_{1}(\omega), \varepsilon_{3}(\omega)$ we will limit ourselves to the high-frequency approximation [1]:

$$
\begin{aligned}
& \varepsilon_{1}\left(\boldsymbol{r}_{\|}-\boldsymbol{r}_{\|}^{\prime}, z, z^{\prime}, t-t^{\prime}\right)=\varepsilon_{0} \varepsilon_{1}(+\infty) \delta\left(t-t^{\prime}\right) \delta\left(\boldsymbol{r}_{\|}-\boldsymbol{r}_{\|}^{\prime}\right) \delta\left(z-z^{\prime}\right), \\
& \varepsilon_{3}\left(\boldsymbol{r}_{\|}-\boldsymbol{r}_{\|}^{\prime}, z, z^{\prime}, t-t^{\prime}\right)=\varepsilon_{0} \varepsilon_{3}(+\infty) \delta\left(t-t^{\prime}\right) \delta\left(\boldsymbol{r}_{\|}-\boldsymbol{r}_{\|}^{\prime}\right) \delta\left(z-z^{\prime}\right),
\end{aligned}
$$

$\varepsilon_{0}$ is dielectric permittivity of vacuum, $\varepsilon_{i}(+\infty)=$ const, $i=1,2$ are high-frequency dielectric constants.

\section{Modeling of dielectric permittivity of ATMF}

To model a dielectric function $\varepsilon_{2}\left(0, z, z^{\prime}, \omega\right)$ of ATMF, we will use the jellium model proposed in [10].

The surface potential is modeled by the rectangular potential well of an infinite depth

$$
U(z)= \begin{cases}\infty & \text { if } z \leqslant 0, z \geqslant l_{\text {well }} \\ 0 & \text { if } 0<z<l_{\text {well }}\end{cases}
$$

here $l_{\text {well }}$ is a width of a potential well. Such a potential allows an analytical solution of the stationary Schrodinger equation $[10,14]$

$$
-\frac{\hbar^{2}}{2 m} \frac{d^{2}}{d z^{2}} \Psi_{n}(\boldsymbol{r})+U(z) \Psi_{n}(\boldsymbol{r})=W_{n} \Psi_{n}(\boldsymbol{r}), \quad \boldsymbol{r}=\left(\boldsymbol{r}_{\|}, z\right),
$$

with homogeneous Dirichlet boundary conditions at the edges of the well

$$
\begin{gathered}
\left.\Psi_{n}(\boldsymbol{r})\right|_{z=0}=\left.\Psi_{n}(\boldsymbol{r})\right|_{z=l_{\text {well }}}=0, \\
\Psi_{n}(\boldsymbol{r})=\sqrt{\frac{2}{S}} e^{i\left(\boldsymbol{k} \cdot \boldsymbol{r}_{\|}\right)} \phi_{n}(z) .
\end{gathered}
$$


$\phi_{n}(z)$ for the potential (6) has a known form [10,14]:

$$
\phi_{n}(z)= \begin{cases}\sqrt{\frac{2}{l_{\text {well }}}} \sin (\alpha z) & \text { if } \quad 0<z<l_{\text {well }}, \\ 0 & \text { if } \quad z \leqslant 0, z \geqslant l_{\text {well }} .\end{cases}
$$

Quantum numbers $\alpha_{n}$ and a maximum number of bound states $n_{\max }$ are given by such relations $[10,14]$ : $\alpha_{n}=\pi n / l_{\text {well }}, n_{\max }=\left[l_{\text {well }} k_{F} / \pi\right]$, where [.] is the ceiling function, $k_{F}=\sqrt{2 m \mu} / \hbar$ is the magnitude of the Fermi wave vector [15], $\mu$ is chemical potential [15].

It is known that the width of the potential well for satisfying the conditions of electroneutrality due to the presence of an exponential "tail" of the electron density does not coincide with the boundaries of the film and depends on the penetration of electrons into the dielectric [10]. As shown in [10],

$$
l_{\text {well }}=l+2 d, \quad d=\frac{3 \pi}{8 k_{F}}+\frac{\pi^{2}}{8 k_{F}^{2} l_{\text {well }}}
$$

is a function of $k_{F}$ and the geometric thickness of the film $l$. Finally [10],

$$
l_{\text {well }}\left(k_{F}\right)=\frac{l}{2}+\frac{3 \pi}{8 k_{F}}+\frac{\sqrt{16 k_{F}^{2} l^{2}+24 \pi k_{F} l+25 \pi^{2}}}{8 k_{F}} .
$$

In this model, we propose to consider Coulomb correlations through their influence on the chemical potential $\mu$ and, consequently, the number of quantization levels $n_{\max }$ only in the dielectric function, neglecting their influence on other parts of the system.

Having the expression for the electron wave function [10] for ATMF, using the results of the work [16], we model $\varepsilon_{2}\left(0, z, z^{\prime}, \omega\right)$ as follows

$$
\varepsilon_{2}\left(0, z, z^{\prime}, \omega\right)=\varepsilon_{2}(z, \omega) \delta\left(z-z^{\prime}\right)=\left(1-\frac{\omega_{p}^{2}}{\pi n_{e} \omega^{2}} \sum_{n=1}^{n_{\max }}\left(k_{F}^{2}-\alpha_{n}^{2}\right)\left|\phi_{n}(z)\right|^{2}\right) \delta\left(z-z^{\prime}\right)
$$

here $\omega_{p}=\sqrt{4 \pi n_{e} e^{2} / m_{e}}$ is a plasma frequency $[1,15], n_{e}$ is an average electron density in ATMF [15].

\section{Plasmon spectrum: simulation results}

Using the results of [12] to calculate the frequency spectrum $\omega\left(k_{x}\right)$ of SPPs, we obtain the following dispersion relation:

$$
e^{-4 k_{1} \frac{l_{w e l l}}{2}}=\frac{k_{1} / \varepsilon_{1}+k_{2} / \varepsilon_{2}}{k_{1} / \varepsilon_{1}+k_{2} / \varepsilon_{2}} \frac{k_{3} / \varepsilon_{1}+k_{3} / \varepsilon_{2}}{k_{3} / \varepsilon_{3}+k_{2} / \varepsilon_{2}}, \quad k_{i}^{2}=k_{x}^{2}-k_{0}^{2} \varepsilon_{i}, \quad i=1,2,3,
$$

in which

$$
\begin{aligned}
& \varepsilon_{2}=\varepsilon_{2}\left(\omega, l_{\text {well }}\right)=1-\frac{\omega_{p}^{2}}{2 \pi n_{e} \omega} \sum_{n=1}^{n_{\max }}\left(k_{F}^{2}-\alpha_{n}^{2}\right){\overline{\left|\phi_{n}(z)\right|^{2}}}^{2}, \\
& {\overline{\mid \phi_{n}(z)}}^{2}=\frac{1}{l_{\text {well }}} \int_{0}^{l_{\text {well }}}\left|\phi_{n}(z)\right|^{2} d z,
\end{aligned}
$$

and $\varepsilon_{1}, \varepsilon_{3}$ are defined by the relations (5).

The simulation was carried out for the parameters that correspond to the structures Vacuum $/ \mathrm{Ag} / \mathrm{Al}_{2} \mathrm{O}_{3}, \mathrm{Vacuum} / \mathrm{Ag} / \mathrm{Si}, \mathrm{SiO}_{2} / \mathrm{Ag} / \mathrm{Si}$ (Table 1). All the parameters we took from $[17,18]$ and from [2] for $\mathrm{Ag}$ on $\mathrm{Si}$ substrate. 
Table 1. The parameters of the structures considered in the simulation.

\begin{tabular}{c|c|c}
\hline Structure & $\varepsilon_{1}$ & $\varepsilon_{2}$ \\
\hline \hline Vacuum $/ \mathrm{Ag} / \mathrm{Al}_{2} \mathrm{O}_{3}$ & 1 & 9 \\
\hline $\mathrm{Vacuum} / \mathrm{Ag} / \mathrm{Si}$ & 1 & 12 \\
\hline $\mathrm{SiO}_{2} / \mathrm{Ag} / \mathrm{Si}$ & 2.4 & 12 \\
\hline
\end{tabular}

Table 2. Comparison with the experiment for $\mathrm{SiO}_{2} / \mathrm{Ag} / \mathrm{Si}$ structure for a film of thickness $l=43.5 a_{0}$ ( $a_{0}$ is Bohr radius). Coulomb correlations, (a); the condition of electroneutrality, (b).

\begin{tabular}{c|c|c|c|c|c|c|c}
\hline \multicolumn{3}{c|}{$k_{x} \approx 0.028 \mathrm{~nm}^{-1}$} & \multicolumn{4}{c}{$k_{x} \approx 0.049 \mathrm{~nm}^{-1}$} \\
\hline \hline$k_{x}$ & $(\mathrm{a})$ & $(\mathrm{b})$ & $(\mathrm{e})$ & $k_{x}$ & $(\mathrm{a})$ & $(\mathrm{b})$ & $(\mathrm{e})$ \\
\hline 0.0278 & 0.696 & 1.288 & 0.62 & 0.0487 & 0.889 & 1.784 & 0.8 \\
\hline
\end{tabular}

The results of simulation of $\omega\left(k_{x}\right)$ for $\mathrm{SiO}_{2} / \mathrm{Ag} / \mathrm{Si}$ structure taking into account the Coulomb correlations are presented in Fig. 1, here we see that oscillations caused by both quantum-size effects and electron density fluctuations in the dielectric/metal interface tend to decrease in amplitude with increasing film thickness.

The comparison with the data obtained for structures Vacuum $/ \mathrm{Ag} / \mathrm{Si}$ and $\mathrm{Al}_{2} \mathrm{O}_{3} / \mathrm{Ag} / \mathrm{Si}$ without taking into account Coulomb correlations demonstrates

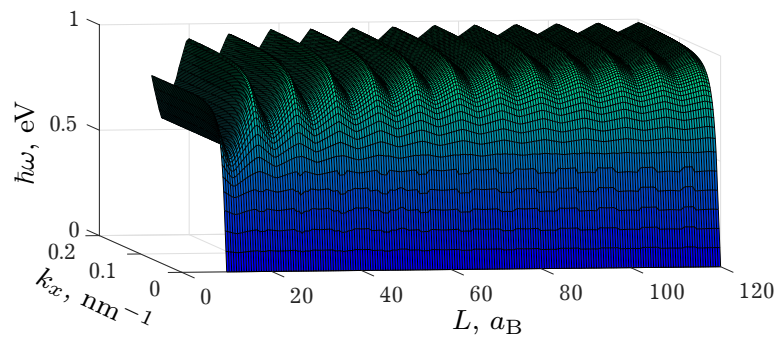

Fig. 1. Dependence of frequency spectrum on ATMF thickness for $\mathrm{SiO}_{2} / \mathrm{Ag} / \mathrm{Si}$ structure taking into account Coulomb correlations. the significant influence of Coulomb correlations on the spectrum $\omega\left(k_{x}\right)$ for ATMF (Fig. 2 and Fig. 3) and the comparison of both results with experimental data for structure $\mathrm{SiO}_{2} / \mathrm{Ag} / \mathrm{Si}$ [2] (Table 2) shows that the calculated values of the spectrum for Coulomb correlations better agree with the experiment.
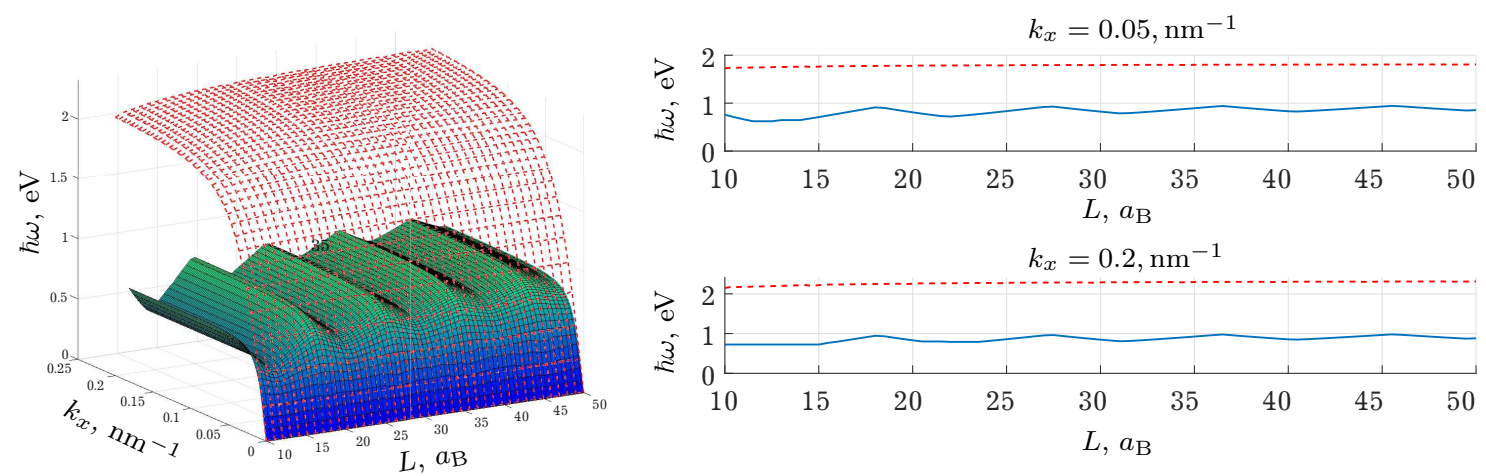

Fig. 2. Comparison of the dependences of the frequency spectrum on the ATMF thickness for the structure $\mathrm{SiO}_{2} / \mathrm{Ag} / \mathrm{Si}$. The condition of electroneutrality, red lines; Coulomb correlations, blue lines.

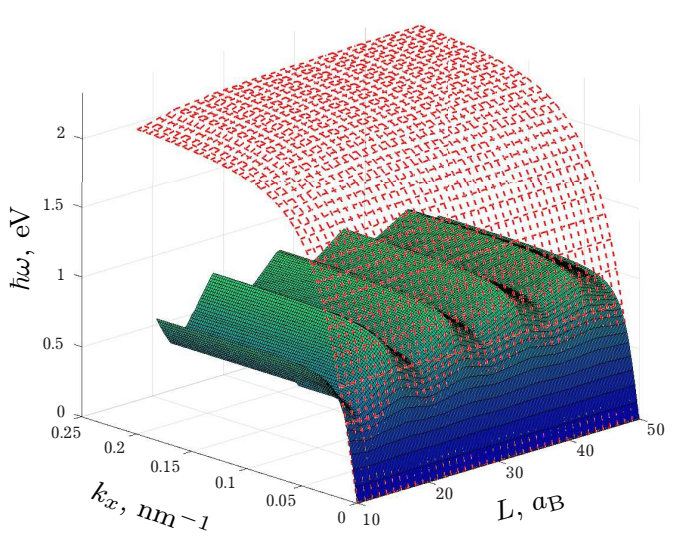

$a$

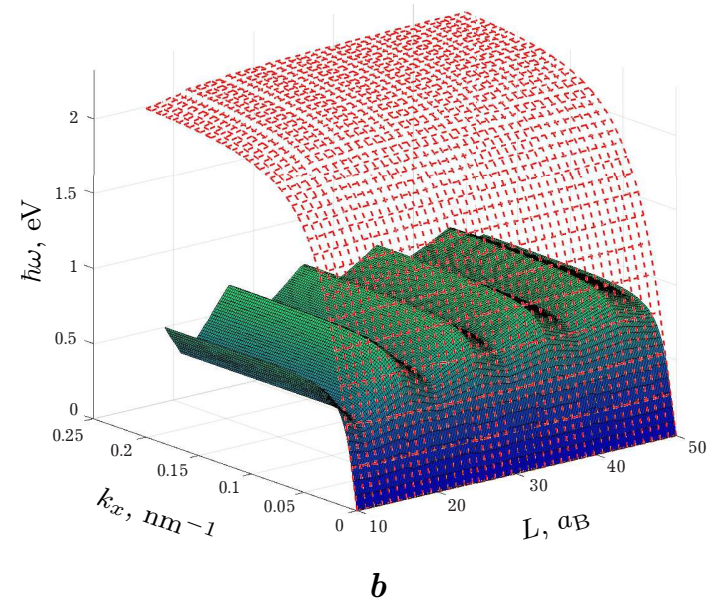

$b$

Fig. 3. Comparison of the dependences of the frequency spectrum on the ATMF thickness for structures: Vacuum $/ \mathrm{Ag} / \mathrm{Si}, \boldsymbol{a} ; \mathrm{Al}_{2} \mathrm{O}_{3} / \mathrm{Ag} / \mathrm{Si}, \boldsymbol{b}$. The condition of electroneutrality, red lines; Coulomb correlations, blue lines. 


\section{Conclusions}

The results show that even a rather "rough" consideration of the Coulomb correlations, namely, their influence on the chemical potential $\mu$, leads to significant changes in the frequency spectrum of SPPs compared to the classical approach and to correct taking into account of the condition of electroneutrality for a non-interacting system of electrons (see Figs. 2,3). This is explained by the fact that in the case of an interacting system, the influence of quantum size effects on $\mu$ increases significantly [10].

The oscillation pattern of the spectrum with an increase in the film thickness $l$ becomes less noticeable (Fig. 1), which coincides with the corresponding behavior of $\mu$ [10], the decay speed of the oscillation peaks also largely depends on the Wigner-Seitz radius $r_{s}$. It is worth noting the dependence of the spectrum on the dielectrics surrounding ATMF which can be seen by comparing the data given in Fig. 2 and Fig. 3.

It is important to note that the inclusion of Coulomb correlations also leads to a significant improvement in the agreement with the experimental data Table 2, and this proves the need to take these correlations into account when modeling the processes of propagation of SPPs waves in ATMF.

[1] Maier S. A. Plasmonics: Fundamentals and Application. Springer-Verlag (2007).

[2] AbdEl-Fattah Z. M., Mkhitaryan V., Brede J., FernándezL., Li Ch., Guo Q., Ghosh A., EcharriA.R., Naveh D., Xia F., Ortega J.E., de Abajo F. J. G. Plasmonics in Atomically-Thin Crystalline Silver Films. ACS Nano. 13 (7), 7771-7779 (2019).

[3] Echarri A. R., Cox J.D., de Abajo F. J. G. Quantum Effects in the Acoustic Plasmons of Atomically-Thin Heterostructures. Optica. 6 (5), 798-798 (2019).

[4] Ando T., Fowler A. B., Stern F. Electronic properties of two-dimensional systems. Rev. Mod. Phys. 54 (2), 437-672 (1982).

[5] Taghizadeh A., Pedersen T. G. Plasmons in ultra-thin gold slabs with quantum spill-qut: Fourier modal method, perturbative approach, and analytical model. Optics Express. 27 (25), 36941-36952 (2019).

[6] Skjølstrup E. J. H., Søndergaard T., Pedersen T. G. Quantum spill-out in few-nanometer metal gaps: Effect on gap plasmons and reflectance from ultrasharp groove arrays. Phys. Rev. B. 97 (11), 115429 (2018).

[7] Skjølstrup E. J. H., Søndergaard T., Pedersen T. G. Quantum spill-out in nanometer-thin gold slabs: Effect on the plasmon mode index and the plasmonic absorption. Phys. Rev. B. 99 (15), 155427 (2019).

[8] Kostrobij P. P., Markovych B. M. The chemical potential and the work function of a metal film on a dielectric substrate. Philosophical Magazine Letters. 99 (1), 12-20 (2019).

[9] Hohenberg P., Kohn W. Inhomogeneous Electron Gas. Phys. Rev. B. 136 (3B), B864-B871 (1964).

[10] Kostrobij P. P., Markovych B. M. Effect of Coulomb interaction on chemical potential of metal film. Philosophical Magazine. 98 (21), 1991-2002 (2018).

[11] Vavrukh M. V., Slobodyan S. B. Electron-plasmon model in the electron liquid theory. Condensed Matter Physics. 8 (3), 453-472 (2005).

[12] Kostrobij P. P., Markovych B. M., Polovyi V. Y. Influence of the electroneutrality of a metal layer on the plasmon spectrum in dielectric-metal-dielectric structures. Mathematical Modeling and Computing. 6 (2), 297-303 (2019).

[13] Jackson J. D. Classical Electrodynamics. John Wiley \& Sons (2007).

[14] Vakarchuk I. O. Kvantova mekhanika. Lviv, LNU im. I. Franka (2007), (in Ukrainian).

[15] Ashcroft N. W, Mermin N. D. Solid State Physics. Cornell University. Harcourt (1976).

[16] Kurbatsky V.P. Dielectric tensor of low-dimensional metal systems. Electronic Properties of Solid. 125 (1), 148-158 (2017).

[17] Korotun A. V. Size oscillations of the work function of a metal film on a dielectric substrate. Phys. Solid State. 57, 391-394 (2015).

[18] Pogosov V. V., Babich A. V., Vakula P. V. On the Influence of the Band Structure of Insulators and Image Forces on the Spectral Characteristics of Metal-Insulator Film Systems. Phys. Solid State. 55, 2120-2123 (2013). 


\title{
Частотний спектр плазмон-поляритонних хвиль: кулонівські кореляції
}

\author{
Костробій П. П., Маркович Б. М., Польовий В. Є. \\ Національний університет "Львівська політехніка", \\ вул. С. Бандери, 12, 79013, Львів, Україна
}

\begin{abstract}
Досліджено модель опису впливу кулонівської взаємодії між електронами (кулонівських кореляцій) на частотний спектр плазмон-поляритонних хвиль елекнонетральних структур діелектрик/метал/діелектрик. Показано, що для атомно тонких металевих плівок (ATMF) врахування таких кореляції впливає як на квантово-розмірну поведінку частотного спектру як функцію товщини металевої плівки так і суттєво покращує кореляцію теоретичних розрахунків та експерименту.
\end{abstract}

Ключові слова: поверхневі плазмони, спектр плазмона, товщина металевого шару, діелектрична проникність, електронейтральність. 